\title{
Conteúdo de reservas, vigor vegetativo e rendimento de videiras submetidas a duas safras por ciclo vegetativo
}

\author{
Content of reserves, vegetative vigor and yield of grapevines \\ submitted to two harvests per vegetative cycle
}

\author{
Rafael Anzanello ${ }^{1 *}$; Paulo Vitor Dutra de Souza ${ }^{2}$
}

\section{Resumo}

Este trabalho visou quantificar as reservas nos ramos e avaliar o vigor vegetativo e rendimento de videiras 'Niagara Branca', 'Niagara Rosada' e 'Concord' submetidas a duas safras de uva por ciclo vegetativo. As plantas foram submetidas à poda de inverno (PI), em cordão esporonado, e à poda verde (PV) no final da primavera, através de desponte dos sarmentos a partir da quarta gema acima do último cacho. Os tratamentos foram: Testemunha 1 (PI em 20-07-07/sem PV), Testemunha 2 (PI em 22-08-07/ sem PV), T1 (PI em 20-07-07/poda verde em 15-11-07), T2 (PI em 20-07-07/PV em 17-12-07); T3 (PI em 22-08-07/PV em 15-11-07) e T4 (PI em 22-08-07/PV em 17-12-07). Avaliaram-se a produção por planta de ambas as safras, o índice de área foliar (IAF) ao longo do ciclo vegetativo e o conteúdo de reservas nos ramos nas seguintes épocas: PI de 2007, floração da primeira safra, PV em 15-11-07, PV em 17-12-07, pós-colheita da primeira e segunda safra e PI de 2008. A execução de uma PI associada a uma PV permitiu a obtenção de duas safras de uva por ciclo vegetativo, sendo mais efetiva no T3. As brotações emitidas pela PV provocaram mudanças no IAF e afetaram a dinâmica de síntese/consumo de reservas nos ramos das plantas. Nas videiras com PV houve redução no teor de reservas ao final do ciclo da cultura, se comparadas às plantas testemunhas. O manejo da poda para obtenção de duas safras aumenta a produção anual, porém acarreta redução no teor de reservas das plantas.

Palavras-chave: Manejo da poda, índice de área foliar, fisiologia vegetal, Vitis labrusca

\begin{abstract}
This study evaluated the content of reserves in the branches and assessed the vegetative vigor and yield of Niagara Branca, Niagara Rosada and Concord grapevines submitted to two harvests per vegetative cycle. The plants were subjected to a winter pruning (WP) performed by means of a short pruning, and to a green pruning (GP) at the end of spring performed by pruning branches from the fourth bud above the last grape cluster. The treatments included Control 1 (WP on 07-20-07/no GP), Control 2 (WP on 0-22-07/no GP), T1 (WP on 07-20-07/GP on 11-15-07), T2 (WP on 07-20-07/GP on 12-1707), T3 (WP on 08-22-07/GP on 11-15-07) and T4 (WP on 08-22-07/GP on 12-17-07). The variables evaluated included grapevine production for the two crops, the leaf area index (LAI) throughout the vegetative cycle, and the content of reserves in the branches in the following stages: $2007 \mathrm{WP}$, first crop flowering, GP on 11-15-07, GP on 12-17-07, post-harvest of first and second crop, and 2008 WP. The WP associated to GP allowed to obtain two harvests in all cultivars being more effective in the T3. The shoots emitted by GP caused changes in the LAI and affected the dynamic of synthesis/ consumption of reserves in the branches of the grapevines. In plants with GP, there was reduction in the content of reserves at the end of the crop cycle compared to control plants. The pruning management to obtain two annual crops increased the annual production, but reduced the level of reserves of the grapevines.

Key words: Pruning management, leaf area index, plant physiology, Vitis labrusca
\end{abstract}

\footnotetext{
${ }^{1}$ Eng $^{\mathrm{O}} \mathrm{Agr}^{\mathrm{O}}$, Pesquisador Dr., Fundação Estadual de Pesquisa Agropecuária, FEPAGRO, Veranópolis, RS. E-mail: rafaelanzanello@fepagro.rs.gov.br

2 Eng $^{\mathrm{o}}$ Agr $^{\mathrm{o}}$, Prof. Dr., Faculdade de Agronomia, PPG Fitotecnia, Universidade Federal do Rio Grande do Sul, UFRGS, Porto Alegre, RS. Bolsista CNPq. E-mail: pvdsouza@ufrgs.br

* Autor para correspondência
} 


\section{Introdução}

O sistema de produção com duas colheitas de uva por ano é comum em alguns países latinoamericanos, dentre eles Brasil, Venezuela e México. Entretanto, há poucos estudos que descrevem a tecnologia usada nesse sistema, assim como a fisiologia relacionada à planta submetida ao respectivo manejo (ANZANELLO; GONZATTO; SOUZA, 2008).

No Rio Grande do Sul há práticas culturais que permitem alterar a fenologia das plantas, pela antecipação da poda de inverno ou seca, e com a aplicação de cianamida hidrogenada, permitindo uma colheita precoce; e pela execução de uma poda verde no final da primavera, através do desponte dos ramos, possibilitando uma segunda colheita no mesmo ciclo vegetativo (SOUZA; FOCHESATO, 2007). Esse manejo é possível em regiões que não apresentam geadas tardias e que tenham temperaturas e insolação elevadas até meados de abril, como a região da Depressão Central do Rio Grande do Sul.

Para Fochesato, Souza e Agostini (2007), o sucesso produtivo da segunda safra no Estado do Rio Grande do Sul está atrelado à combinação entre épocas específicas de poda de inverno e poda verde. Souza e Fochesato (2007) afirmam que a poda verde, se realizada precocemente, leva a uma pequena produção, devido à insuficiente diferenciação de gemas. E, se executada tardiamente, pode não atingir o ponto de maturação ideal em virtude da mesma ocorrer no outono, época de baixas temperaturas e insolação.

Em outras regiões do Brasil, como o norte do Paraná, interior de São Paulo e sul de Minas Gerais, duas safras de uva são comumente obtidas pelo manejo da dupla poda. Nestes casos, a produção de uva de mesa é realizada mediante a realização de uma poda no inverno, no final do repouso hibernal, nos meses de julho e agosto, com a realização da colheita em dezembro e janeiro. E, outra poda no verão, imediatamente após a colheita da safra originada pela poda de inverno, com realização da colheita entre maio e junho, propiciando uma safra extratemporã (RICCE; CARAMORI; ROBERTO, 2013). Este manejo resulta em alterações na fenologia da planta e deslocamento da produção extratemporã para épocas mais favoráveis à comercialização (SANTOS et al., 2011). Entretanto, Santos et al. (2011) afirmam que os níveis de reservas da planta podem ser afetados pelo cultivo contínuo, suscitando atenção quanto ao manejo da cultura em cultivo de dupla poda.

Para Giovaninni (2008) e Santos, Moreira e Rodrigues (2013), o manejo da videira deve buscar manter o equilíbrio da distribuição das reservas entre o sistema vegetativo e reprodutivo das plantas. Segundo Smith e Holzapfel (2009) a dinâmica do conteúdo de reservas na videira é influenciada por variações sazonais e fenológicas. No início do crescimento vegetativo da videira, a maioria dos carboidratos transportados para as folhas e ramos em desenvolvimento tem origem nas reservas acumuladas pelas plantas na pós-colheita do ciclo anterior. Já, após o florescimento, os carboidratos são direcionados, prioritariamente, para os frutos e estruturas de reserva, sendo a área foliar da planta determinante sobre o acúmulo de reservas na mesma (FERREE; MCARTNEY; SCURLOCK, 2001; BATES; DUNST; JOY, 2002). O manejo da dupla poda, por modificar aspectos fisiológicos na planta, necessita ser melhor avaliado e comparado ao manejo convencional (uma única poda), quanto à dinâmica do acúmulo de reservas e suas reais consequências geradas às plantas.

Conforme Zapata et al. (2004), os carboidratos encontram-se em maior concentração nos tecidos perenes da videira durante a abscisão foliar e decrescem até o início da brotação. Para Marenco e Lopes (2005) e Bennett et al. (2005), a partição e a mobilização de reservas nos órgãos vegetativos da videira refletem o efeito que determinadas práticas culturais, tais como tipo de poda, desbrota de ramos e folhas, apresentam sobre os processos fisiológicos da planta. Para Madero e López (1993), videiras 
submetidas a duas safras de uva por ciclo vegetativo, através de podas consecutivas, podem diminuir o conteúdo de reservas das plantas e comprometer sua vida útil. Entretanto, estas são hipóteses que precisam ser avaliadas e/ou confirmadas.

Os sistemas de poda alteram a arquitetura das plantas, mudando, consequentemente, seu dossel vegetativo e, por conseguinte, provocam alterações no teor de reservas (ZAPATA et al., 2004; OLIVEIRA et al., 2007). Borba, Filho e Kluge (2005) verificaram que o metabolismo de carboidratos, especialmente durante o início de crescimento, é diferente em plantas de pessegueiro podadas e não podadas. Para Souza e Fochesato (2007), a produção de duas safras por ciclo vegetativo em videiras deve estar associada à capacidade da planta sintetizar e/ou translocar, a partir da poda verde, fotoassimilados suficientes para suprir as demandas da frutificação da primeira safra e, paralelamente, as necessidades para o crescimento dos órgãos vegetativos responsáveis pela segunda produção.

O objetivo deste trabalho foi avaliar o conteúdo de reservas, o vigor vegetativo e o rendimento de videiras 'Niagara Branca', 'Niagara Rosada' e 'Concord' submetidas a diferentes épocas de poda seca e de poda verde visando a obtenção de duas safras de uva por ciclo vegetativo da videira, na região da Depressão Central do Rio Grande do Sul, safra de 2007/2008.

\section{Material e Métodos}

O experimento foi conduzido na região da Depressão Central do Rio Grande do Sul. O solo do local é classificado como Argissolo Vermelho Distrófico de textura argilosa e relevo ondulado, tendo como substrato o granito. Normalmente são solos bem drenados, fortemente ácidos, com saturação e soma de bases baixa e com teores baixos de matéria orgânica. Segundo Köppen, o clima da região é classificado como Cfa. A precipitação pluviométrica anual média é de 1.445,8 mm e a umidade relativa do ar anual média é $77 \%$. A radiação solar global média é de $12,39 \mathrm{MJ} \mathrm{m}^{-2}$ dia $^{-1}$. $\mathrm{O}$ número médio de horas de frio com temperaturas inferiores a $7,2^{\circ} \mathrm{C}$ é de 213 horas de maio a agosto (BERGAMASCHI et al., 2003).

Para o experimento utilizaram-se três cultivares de videira, Niagara Branca, Niagara Rosada e Concord, enxertadas sobre o porta-enxerto 101-14 mgt, com 16 anos de idade. As plantas encontravamse espaçadas por 1,20 m dentro da fila e 3,00 m entre filas, conduzidas em sistema de espaldeira, com 3 fios de arame, espaçados $55 \mathrm{~cm}$ cada.

$\mathrm{O}$ delineamento experimental utilizado foi $\mathrm{o}$ completamente casualizado com oito repetições por tratamento, sendo testadas duas épocas de poda de inverno e duas épocas de poda verde. As podas de inverno foram realizadas em julho (20/07/07) e agosto $(22 / 08 / 07)$ e as podas verdes em novembro $(15 / 11 / 07)$ e dezembro (17/12/07). Os tratamentos consistiram de: Testemunha 1 - Poda de inverno em julho - sem poda verde (PIJ), Testemunha 2 - Poda de inverno em agosto - sem poda verde (PIA); T1 - Poda de inverno em julho e poda verde em novembro (PIJ + PVN); T2 - Poda de inverno em julho e poda verde em dezembro (PIJ + PVD); T3 - Poda de inverno em agosto e poda verde em novembro (PIA + PVN); T4 - Poda de inverno em agosto e poda verde em dezembro (PIA + PVD).

A poda de inverno consistiu em deixar duas a três gemas por ramo, em cordão esporonado, restando 35 a 40 gemas planta $^{-1}$. Todas as plantas foram submetidas à superação de dormência mediante pulverização de cianamida hidrogenada a $2 \%$, imediatamente após a poda seca. Já, a poda verde foi feita mediante o desponte do sarmento a partir da quarta gema acima do último cacho, e a eliminação das feminelas ou netos, forçando a brotação das gemas francas. As plantas testemunhas somente receberam desponte do sarmento acima do $3^{\circ}$ fio de arame, o que correspondeu a mais de oito folhas acima do último cacho.

Durante o período experimental realizaram-se amostragens de ramos para determinar o teor de 
reservas totais. As épocas de coleta foram: poda de inverno de 2007, floração da primeira safra, poda verde em 15/11/07, poda verde em 17/12/07, póscolheita da primeira safra, pós-colheita da segunda safra e poda de inverno de 2008. Os ramos coletados corresponderam as brotações provenientes da poda de inverno, retirados a aproximadamente $10 \mathrm{~cm}$ do eixo principal da planta, medindo de 60 a $80 \mathrm{~cm}$ de comprimento e, cerca de, $1 \mathrm{~cm}$ de diâmetro. Em cada data de coleta foram amostrados oito ramos por tratamento (um ramo por unidade experimental) nas plantas submetidas à poda verde e nas plantas testemunhas. Na primeira e última coleta os ramos encontravam-se lignificados e dormentes. Nas coletas intermediárias os ramos encontravam-se lignificados ou herbáceos, conforme a época de amostragem, e em estádio vegetativo.

Os ramos, após a coleta, foram acondicionados em sacos de papel e postos a secar em estufa a $65^{\circ} \mathrm{C}$, até massa constante. Após, o material foi moído em moinho acoplado com peneira de 20 malhas por polegada quadrada. Para cada época de coleta e tratamento, os ramos moídos foram acondicionados em saquinhos feitos de "tela especial para filtragem de alimentos", contendo 1,5 g de amostra. As bordas dos saquinhos foram amarradas com fio de nylon, para impedir a perda de material, formando pequenas trouxas. Estas foram identificadas individualmente e, novamente, levadas à estufa a $65^{\circ} \mathrm{C}$, até massa constante. As trouxas foram submetidas à digestão, segundo adaptações do método de Priestley (1965), para extrair toda e qualquer substância de reserva e produtos sintetizados pelas plantas, tais como carboidratos, gorduras e ácidos graxos, permanecendo somente as fibras. As amostras foram colocadas em Erlenmayer de $1 \mathrm{~L}$, com solução aquosa contendo 5\% de ácido tricloroacético (99,0\%) e 35\% de metanol (99,8\%), permanecendo sob aquecimento em bico de Bunsen, em capela com exaustor, por 8 horas. Nas duas primeiras horas, a solução contendo as amostras permaneceu em ebulição. A partir daí, até completar às 8 horas, foi-se adicionando água destilada à solução à medida que esta ia evaporando, visando manter sempre o mesmo volume de líquido para que as amostras se mantivessem imersas à solução. Concluído o processo, as amostras foram lavadas com água destilada e postas a secar novamente em estufa a $65^{\circ} \mathrm{C}$ até massa constante. A diferença de massa das amostras antes e após a digestão consistiu no teor de reservas, expresso em porcentagem (\%).

A área foliar das plantas foi avaliada ao longo do ciclo vegetativo da videira submetida às duas safras. $O$ índice de área foliar (IAF) foi determinado de forma não destrutiva, pelo método descrito por Carbonneau (1976), com algumas adaptações. Para a calibração do método, foram coletadas 150 folhas por tratamento, e sua área medida em planímetro eletrônico LI-COR, modelo LI 3000. Foram realizadas contagens de folhas das oito plantas por tratamento, quinzenalmente, e medidas as dimensões de comprimento e largura de 15 folhas por planta. A área média das folhas (AF), calculada através da multiplicação entre comprimento e largura do limbo foliar, foi multiplicada pelo número de folhas por planta (NF), para estimar a área foliar média por planta e posterior estimativa de IAF, segundo a fórmula:

$$
\mathrm{IAF}=(\mathrm{NF} X \mathrm{AF}) / \mathrm{S}
$$

Sendo: NF o número de folhas por planta; AF a área média das folhas por planta e $\mathrm{S}$ a área de solo ocupada por planta.

A relação folha:fruto foi obtida segundo método proposto por Alleweldt e Fader, citados por Casteran (1971), baseado na quantificação da área foliar $\left(\mathrm{m}^{2}\right)$, e na massa de cachos produzida por planta $(\mathrm{kg})$. A relação folha:fruto foi contabilizada da virada de cor das bagas à colheita nas cvs. Niagara Rosada e Concord e, do início da maciez das bagas à colheita na cv. Niagara Branca, para todos os tratamentos.

A produção por planta, em $\mathrm{kg}$, foi registrada para as duas safras do ciclo vegetativo. Os cachos colhidos tiveram sua massa anotada, em $\mathrm{kg}$, através de pesagem em balança eletrônica, marca Urano, modelo UDC 30000/5. A produção dos 
ramos retirados para a análise de reservas não foi desprezada, sendo estimada pela razão alcançada entre a produção colhida e os ramos remanescentes na planta.

As variáveis de produção, IAF e conteúdo de reservas nos ramos foram submetidos à análise de variância. Os resultados com diferenças significativas, pelo teste "F", tiveram suas médias submetidas ao teste de Tukey ao nível de significância de $5 \%$.

\section{Resultados e Discussão}

A produção da primeira safra de uva obtida ao longo dos meses de dezembro e janeiro, para as cultivares Niagara Branca, Niagara Rosada e Concord, é apresentada na Tabela 1. O rendimento médio por planta não variou entre a 'Niagara Branca' e 'Niagara Rosada', porém diferiu significativamente para a 'Concord', que apresentou menor produtividade por planta. Tais características devem-se, provavelmente, às diferenças genéticas inerentes às cultivares (CAMARGO, 2003). Não houve diferenças em produtividade entre as diferentes épocas de poda de inverno, alcançando na média entre os tratamentos, 31,3 $\mathrm{t} \mathrm{ha}^{-1}$ para a 'Niagara Branca', 29,5 tha ${ }^{-1}$ para a 'Niagara Rosada' e 22,1 t ha- ${ }^{-1}$ para a 'Concord', sendo superior a média do Rio Grande do Sul para as três cultivares, a qual é de 15 a $20 \mathrm{t} \mathrm{ha}^{-1}$ (GIOVANINNI, 2008).
A alta produtividade obtida pelas cultivares na primeira produção deve-se, dentre as razões, a elevada carga de gemas planta $^{-1}$ deixadas na poda de inverno(aproximadamente 60-70 gemas). Associado a isto, tem-se a boa adaptação edafoclimática dos genótipos trabalhados a região de cultivo, além do manejo fitossanitário e nutricional adequados no vinhedo. Para Santos et al. (2011) a alta produção da primeira safra pode influenciar a segunda safra da planta, pois tende a reduzir o balanço de reservas acumuladas, além de poder provocar enfraquecimento da planta, alternância de produção e encurtamento da vida útil da videira.

Para a segunda produção, o tratamento T3 $(\mathrm{PIA}+\mathrm{PVN})$ proporcionou maior produção por planta, indicando a importância da combinação entre as épocas de poda de inverno e poda verde para o sucesso da colheita (Tabela 1). A cultivar Niagara Branca foi a mais propensa para a adoção do manejo estabelecido, proporcionando uma produtividade na segunda safra equivalente a 3.500 kg ha-1, seguida pela 'Niagara Rosada', com uma produtividade de $2.333 \mathrm{~kg} \mathrm{ha}^{-1}$, e pela 'Concord' com $1.333 \mathrm{~kg} \mathrm{ha}^{-1}$. Com a produção oriunda da poda verde, um incremento na produção total anual de uva seria obtido, significando um ganho extra e ampliação da disponibilidade da fruta, pela segunda produção ser alcançada em meados de março/abril. Para Giovaninni (2008), a fenologia das cultivares Niagara Branca, Niagara Rosada e Concord compreende um período de colheita concentrado, principalmente, no mês de janeiro, no Estado do Rio Grande do Sul. 
Tabela 1. Produção média por planta na primeira e segunda colheita das cultivares Niagara Branca (NB), Niagara Rosada (NR) e Concord. Eldorado do Sul, RS, 2007/2008.

\begin{tabular}{|c|c|c|c|c|c|c|}
\hline \multirow[b]{2}{*}{ Cultivar } & \multicolumn{6}{|c|}{ Produção média $\left(\mathrm{kg} \mathrm{planta}^{-1}\right)$ primeira safra - safra regular } \\
\hline & $\begin{array}{c}\text { Testemunha } 1^{(2)} \\
\text { (PIJ) }\end{array}$ & $\begin{array}{c}\text { Testemunha } 2 \\
\text { (PIA) }\end{array}$ & $\begin{array}{c}\mathrm{T} 1 \\
(\mathrm{PIJ}+\mathrm{PVN})\end{array}$ & $\begin{array}{c}\mathrm{T} 2 \\
(\mathrm{PIJ}+\mathrm{PVD})\end{array}$ & $\begin{array}{c}\mathrm{T} 3 \\
(\mathrm{PIA}+\mathrm{PVN})\end{array}$ & $\begin{array}{c}\text { T4 } \\
\text { (PIA }+ \\
\text { PVD) }\end{array}$ \\
\hline NB & $11,54 \mathrm{aA}^{(1)}$ & $12,03 \mathrm{aA}$ & $11,06 \mathrm{aA}$ & $11,78 \mathrm{aA}$ & $10,15 \mathrm{aA}$ & $11,03 \mathrm{aA}$ \\
\hline NR & $10,31 \mathrm{aA}$ & $11,02 \mathrm{aA}$ & $10,58 \mathrm{aA}$ & $10,95 \mathrm{aA}$ & $10,17 \mathrm{aA}$ & $10,72 \mathrm{aA}$ \\
\hline Concord & $7,56 \mathrm{aB}$ & $8,05 \mathrm{aB}$ & $8,17 \mathrm{aB}$ & $8,34 \mathrm{aB}$ & $7,71 \mathrm{aB}$ & $7,94 \mathrm{aB}$ \\
\hline CV $(\%)$ & \multicolumn{6}{|c|}{23,98} \\
\hline \multirow[b]{2}{*}{ Cultivar } & \multicolumn{6}{|c|}{ Produção média $\left(\mathrm{kg} \mathrm{planta}^{-1}\right)$ segunda safra - safra extratemporã } \\
\hline & $\begin{array}{c}\text { Testemunha } 1^{(2)} \\
\text { (PIJ) }\end{array}$ & $\begin{array}{l}\text { Testemunha } 2 \\
\text { (PIA) }\end{array}$ & $\begin{array}{c}\text { T1 } \\
(\mathrm{PIJ}+\mathrm{PVN})\end{array}$ & $\begin{array}{c}\mathrm{T} 2 \\
(\mathrm{PIJ}+\mathrm{PVD})\end{array}$ & $\begin{array}{c}\mathrm{T} 3 \\
(\mathrm{PIA}+\mathrm{PVN})\end{array}$ & $\begin{array}{c}\text { T4 } \\
\text { (PIA }+ \\
\text { PVD) } \\
\end{array}$ \\
\hline NB & $---^{(3)}$ & --- & $0,31 \mathrm{bA}$ & $0,28 \mathrm{bA}$ & $1,26 \mathrm{aA}$ & $0,34 \mathrm{bA}$ \\
\hline NB & --- & --- & $0,21 \mathrm{bA}$ & $0,25 \mathrm{bA}$ & $0,84 \mathrm{aB}$ & $0,24 \mathrm{bA}$ \\
\hline Concord & --- & --- & $0,16 \mathrm{bA}$ & $0,18 \mathrm{bA}$ & $0,48 \mathrm{aC}$ & $0,19 \mathrm{bA}$ \\
\hline CV $(\%)$ & \multicolumn{6}{|c|}{15,95} \\
\hline \multicolumn{7}{|c|}{$\begin{array}{l}\text { (1) Médias seguidas pela mesma letra, minúscula na linha e maiúscula na coluna, não diferem significativamente pelo teste de Tukey, } \\
\text { p }<0,05 .{ }^{(2)} \text { Testemunha } 1 \text { - Poda de inverno em julho - sem poda verde (PIJ), Testemunha } 2 \text { - Poda de inverno em agosto - sem poda } \\
\text { verde (PIA); T1 - Poda de inverno em julho e poda verde em novembro (PIJ + PVN); T2 - Poda de inverno em julho e poda verde } \\
\text { em dezembro (PIJ + PVD); T3 - Poda de inverno em agosto e poda verde em novembro (PIA + PVN); T4 - Poda de inverno em } \\
\text { agosto e poda verde em dezembro (PIA + PVD). }{ }^{(3)} \text { Dados não obtidos, pelo tratamento Testemunha corresponder apenas à primeira } \\
\text { safra. } \\
\text { Fonte: Elaboração dos autores. }\end{array}$} \\
\hline
\end{tabular}

A maior brotação do tratamento T3 (PIA + PVN) pode também ter sido influenciada pelo balanço hormonal da planta. Junto à brotação, há necessidade de alta relação citocinina/giberelina endógena (SHALTOUT; SALEM; KILANY, 1988). Dessa forma, como a poda verde no tratamento T3 (PIA + PVN) foi realizada quando os frutos da primeira safra se encontravam na fase de "ervilha", e nos demais tratamentos, a mesma foi executada numa fase mais avançada de desenvolvimento do cacho, a maior síntese de giberelinas causada pela presença de sementes maiores e mais maduras nos tratamentos T1 (PIJ + PVN), T2 (PIJ + PVD) e T4 (PIA + PVD) pode ter-se tornado um fator impeditivo à brotação das gemas, por ter diminuído a relação citocinina/giberelina presente na planta.

O comportamento de resposta do teor de reservas foi semelhante ao longo do ciclo da cultura para as três cultivares em estudo ('Niagara Branca', 'Niagara Rosada' e 'Concord') (Figuras 1A, 1B e 1C). Da poda à floração, verificou-se um conteúdo menor de reservas nos ramos das plantas para todos os tratamentos estudados $(\mathrm{p}<0,05)$. Isto se deve as brotações, neste estádio, serem novas, com baixo potencial de síntese de reservas. Bates, Dunst e Joy (2002) e Zapata et al. (2004) relatam que no início da brotação da videira, os ramos se desenvolvem às expensas das reservas das estruturas permanentes (braços, tronco e raízes) da planta. Neste momento, os primeiros produtos da fotossíntese são utilizados para expandir o crescimento vegetativo dos ramos, em detrimento ao acúmulo de reservas (BOLDING; SMITH; KLAGES, 2003; KLIEWER; DOKOOZLIAN, 2005).

Após a floração, um aumento no conteúdo de reservas nos ramos foi verificado para todos os tratamentos $(\mathrm{p}<0,05)$ (Figuras 1A, 1B e 1C). Nas plantas testemunhas (PIJ e PIA), o teor de reservas foi significativamente maior a partir da póscolheita da primeira safra, se comparado às plantas submetidas à poda verde (T1: PIJ + PVN, T2: PIJ + PVD; T3: PIA + PVN e T4: PIA + PVD). Segundo 
Lebon et al. (2008), os compostos orgânicos produzidos através da fotossíntese, após a floração da videira, são translocados concomitantemente para o desenvolvimento dos frutos e para as estruturas de armazenamento de reservas da planta, até a abscisão foliar. Em macieira, Yoshioka et al. (1988) também observaram que a partir do florescimento, os carboidratos fotossintetizados na estação corrente passaram a suprir não só o desenvolvimento dos frutos e a respiração da planta, como também a reposição dos tecidos de reserva.

Nas plantas testemunhas (PIJ e PIA), a excessiva carga de frutos da primeira safra (Tabela 1) resultou numa relação IAF: fruto de 1,03 a $1,16 \mathrm{~m}^{2} \mathrm{~kg}^{-1}$ entre as cultivares (Tabela 2), abaixo do especificado por Alleweldt e Fader, citado por Casteran (1971), que afirmam que para uvas de mesa é necessária uma superfície foliar de $2,14 \mathrm{~m}^{2} \mathrm{~kg}^{-1}$ para um bom equilíbrio nutricional e energético da planta. Conforme Mullins, Bouquet e Williams (2000), o excesso de frutos induz a videira alocar reservas armazenadas de suas estruturas permanentes para suprir o desenvolvimento dos frutos da estação. Para uvas de vinho fino, Keller et al. (2005) e Kliewer e Dokoozlian (2005) afirmam que para uma maturação adequada, a razão área foliar:fruto deve estar entre 0,8 a $1,2 \mathrm{~m}^{2} \mathrm{~kg}^{-1}$.

Nas plantas submetidas à poda verde (T1: PIJ + PVN; T2: PIJ + PVD; T3: PIA + PVN e T4: PIA + PVD), o conteúdo de reservas inferior ao das plantas testemunhas (PIJ e PIA), após a floração (Figuras 1A, 1B e 1C), ocorreu devido à redução da sua superfície foliar pela ação da poda verde (Figuras 1D, 1E e 1F). Houve também uma provável translocação das reservas dos ramos do ano para o crescimento das brotações responsáveis pela segunda safra. De acordo com Wermelinger, Baumgärtnerand e Gutierrez (1991), o crescimento vegetativo de feminelas e/ou brotações produtivas, a partir dos ramos do ano, são provenientes da atividade fotossintética das folhas e das próprias reservas acumuladas nos sarmentos.

Tabela 2. Área foliar por fruto, em $\mathrm{m}^{2} \mathrm{~kg}^{-1}$, na primeira e segunda safra das cultivares Niagara Branca (NB), Niagara Rosada (NR) e Concord. Eldorado do Sul, RS, 2007/2008.

\begin{tabular}{|c|c|c|c|c|c|c|}
\hline \multirow[b]{2}{*}{ Cultivar } & \multicolumn{6}{|c|}{ Área foliar/fruto $\left(\mathrm{m}^{2} \mathrm{~kg}^{-1}\right)$ primeira safra - safra regular } \\
\hline & $\begin{array}{c}\text { Testemunha } 1^{(2)} \\
\text { (PIJ) }\end{array}$ & $\begin{array}{c}\text { Testemunha } 2 \\
\text { (PIA) }\end{array}$ & $\begin{array}{c}\mathrm{T} 1 \\
(\mathrm{PIJ}+\mathrm{PVN})\end{array}$ & $\begin{array}{c}\text { T2 } \\
(\mathrm{PIJ}+\mathrm{PVD})\end{array}$ & $\begin{array}{c}\text { T3 } \\
(\mathrm{PIA}+\mathrm{PVN})\end{array}$ & $\begin{array}{c}\text { T4 } \\
\text { (PIA + } \\
\text { PVD) }\end{array}$ \\
\hline NB & $1,10 \mathrm{aA}^{(1)}$ & $1,08 \mathrm{aA}$ & $0,49 \mathrm{bA}$ & $0,61 \mathrm{bA}$ & $0,71 \mathrm{bA}$ & $0,57 \mathrm{bA}$ \\
\hline NR & $1,03 \mathrm{aA}$ & $1,07 \mathrm{aA}$ & $0,46 \mathrm{bA}$ & $0,59 \mathrm{bA}$ & $0,61 \mathrm{bA}$ & $0,54 \mathrm{bA}$ \\
\hline Concord & $1,13 \mathrm{aA}$ & $1,16 \mathrm{aA}$ & $0,53 \mathrm{bA}$ & $0,73 \mathrm{bA}$ & $0,71 \mathrm{bA}$ & $0,69 \mathrm{bA}$ \\
\hline $\mathrm{CV}(\%)$ & \multicolumn{6}{|c|}{22,45} \\
\hline & \multicolumn{6}{|c|}{ Área foliar/fruto $\left(\mathrm{m}^{2} \mathrm{~kg}^{-1}\right)$ segunda safra - safra extratemporã } \\
\hline Cultivar & $\begin{array}{c}\text { Testemunha } 1^{(2)} \\
\text { (PIJ) }\end{array}$ & $\begin{array}{c}\text { Testemunha } 2 \\
\text { (PIA) }\end{array}$ & $\begin{array}{c}\mathrm{T} 1 \\
(\mathrm{PIJ}+\mathrm{PVN})\end{array}$ & $\begin{array}{c}\mathrm{T} 2 \\
(\mathrm{PIJ}+\mathrm{PVD})\end{array}$ & $\begin{array}{c}\mathrm{T} 3 \\
(\mathrm{PIA}+\mathrm{PVN})\end{array}$ & $\begin{array}{c}\text { T4 } \\
\text { (PIA + } \\
\text { PVD) }\end{array}$ \\
\hline NB & $--^{(3)}$ & --- & $8,61 \mathrm{aB}$ & $9,03 \mathrm{aB}$ & $5,14 \mathrm{bB}$ & $8,48 \mathrm{aB}$ \\
\hline NR & --- & --- & $9,24 \mathrm{aAB}$ & $8,94 \mathrm{aB}$ & $5,95 \mathrm{bB}$ & $9,18 \mathrm{aAB}$ \\
\hline Concord & --- & --- & $10,49 \mathrm{aA}$ & $11,37 \mathrm{aA}$ & $8,43 \mathrm{bA}$ & $10,35 \mathrm{aA}$ \\
\hline $\mathrm{CV}(\%)$ & \multicolumn{6}{|c|}{19,03} \\
\hline
\end{tabular}

${ }^{(1)}$ Médias seguidas pela mesma letra, minúscula na linha e maiúscula na coluna, não diferem significativamente pelo teste de Tukey, $\mathrm{p}<0,05 .{ }^{(2)}$ Testemunha 1 - Poda de inverno em julho - sem poda verde (PIJ), Testemunha 2 - Poda de inverno em agosto - sem poda verde (PIA); T1 - Poda de inverno em julho e poda verde em novembro (PIJ + PVN); T2 - Poda de inverno em julho e poda verde em dezembro (PIJ + PVD); T3 - Poda de inverno em agosto e poda verde em novembro (PIA + PVN); T4 - Poda de inverno em agosto e poda verde em dezembro (PIA + PVD). ${ }^{(3)}$ Dados não obtidos, pelo tratamento Testemunha corresponder apenas à primeira safra.

Fonte: Elaboração dos autores. 
A menor relação IAF: fruto da primeira colheita nas plantas submetidas à poda verde (T1: PIJ + PVN, T2: PIJ + PVD, T3: PIA + PVN e T4: PIA + PVD) em relação às plantas testemunhas (PIJ e PIA) (Tabela 2) afetou negativamente o equilíbrio nutricional da parreira. Houve atraso na colheita da primeira produção em até 10 dias para a 'Niagara Branca' e 'Niagara Rosada' e de 13 dias para a 'Concord' das plantas podadas para as não podadas no final da primavera. Resultados semelhantes foram obtidos por Souza e Fochesato (2007), na cultivar Niagara Branca, que obtiveram um atraso de uma semana na primeira colheita com o emprego da poda verde. A relação IAF:fruto entre as cultivares não se distinguiu na primeira safra, apesar da diferença de produtividade apresentada entre elas (Tabela 1 e 2).

Os brotos das plantas expostas a segunda safra (T1: PIJ + PVN; T2: PIJ + PVD; T3: PIA + PVN e T4: PIA + PVD), ao tornarem-se autotróficos, promoveram um aumento significativo no conteúdo de reservas dos ramos da pós-colheita da primeira safra à pós-colheita da segunda safra $(p<0,05)$, nas cultivares Niagara Branca, Niagara Rosada e Concord (Figuras 1A, 1B e 1C). Para Marenco e Lopes (2005) um mesmo órgão pode funcionar como dreno durante um período do seu desenvolvimento e depois se converter em fonte. As folhas, nos estágios iniciais de desenvolvimento, representam drenos, recebendo fotoassimilados para atender às exigências do metabolismo ativo. Ao atingirem o tamanho máximo, a taxa de crescimento diminui, assim como a demanda metabólica, passando gradualmente à condição de órgão exportador. Ao final do ciclo da cultura, o conteúdo de reservas dos ramos submetidos à segunda safra (T1: PIJ + PVN; T2: PIJ + PVD; T3: PIA + PVN e T4: PIA + PVD) foi significativamente menor que o teor acumulado pelas plantas testemunhas (PIJ e PIA) (Figuras 1A, 1B e 1C), indicando que a realização de duas colheitas por ciclo vegetativo reduz o conteúdo de reservas totais acumulado nas plantas.
Em todas as cultivares, o tratamento T3 $($ PIA + PVN), por apresentar maior número de brotações originárias da poda verde, demandou maior consumo de reservas dos sarmentos para o crescimento dos novos ramos, se comparado aos tratamentos T1 (PIJ + PVN), T2 (PIJ + PVD) e T4 (PIA + PVD). Essa redução é observada da poda verde de 17/12/07 à pós-colheita da primeira safra (Figuras 1A, 1B e 1C). Já, posteriormente, a área foliar fotossintética superior do tratamento T3 (PIA + PVN) (Figuras 1D, 1E e 1F) proporcionou maior produção de fotoassimilados, sendo usados para suprir o desenvolvimento dos frutos da segunda produção e reabastecer as fontes de reserva da planta. Este comportamento foi mais marcante no tratamento T3 $(\mathrm{PIA}+\mathrm{PVN})$ da 'Niagara Branca' (Figura 1A), em que a síntese de compostos orgânicos no final do ciclo repôs significativamente as reservas da planta gastas para o crescimento das brotações responsáveis pela segunda safra $(p<0,05)$.

No desenvolvimento dos frutos da segunda safra, os fotoassimilados provenientes da atividade fotossintética possivelmente tenham sido a principal fonte de nutrição dos frutos. Houve diferença na relação IAF:fruto entre cultivares e tratamentos de poda (Tabela 2). A relação área foliar:fruto de 5,14 $\mathrm{m}^{2} \mathrm{~kg}^{-1}$ para a 'Niagara Branca', 5,95 $\mathrm{m}^{2} \mathrm{~kg}^{-1}$ para a 'Niagara Rosada' e 8,43 $\mathrm{m}^{2} \mathrm{~kg}^{-1}$ para a 'Concord', referente ao tratamento T3 (PIA + PVN) (Tabela $2)$, mostrou-se eficiente para atender a demanda energética para o desenvolvimento dos frutos da segunda produção, assim como para armazenar reservas nos ramos (Figuras 1A, 1B e 1C). De acordo com Marenco e Lopes (2005), uma menor produção de frutos resulta em menor força de dreno, ocasionando um balanço positivo de fotoassimilados nas folhas, maior crescimento vegetativo e acúmulo de reservas nas estruturas da planta. 
Figura 1. Teor de reservas nos ramos e IAF das cvs. Niagara Branca (1A, 1D), Niagara Rosada (1B, 1E) e Concord (1C, 1F) submetidas a duas safras por ciclo vegetativo. Eldorado do Sul, RS, 2007/2008.
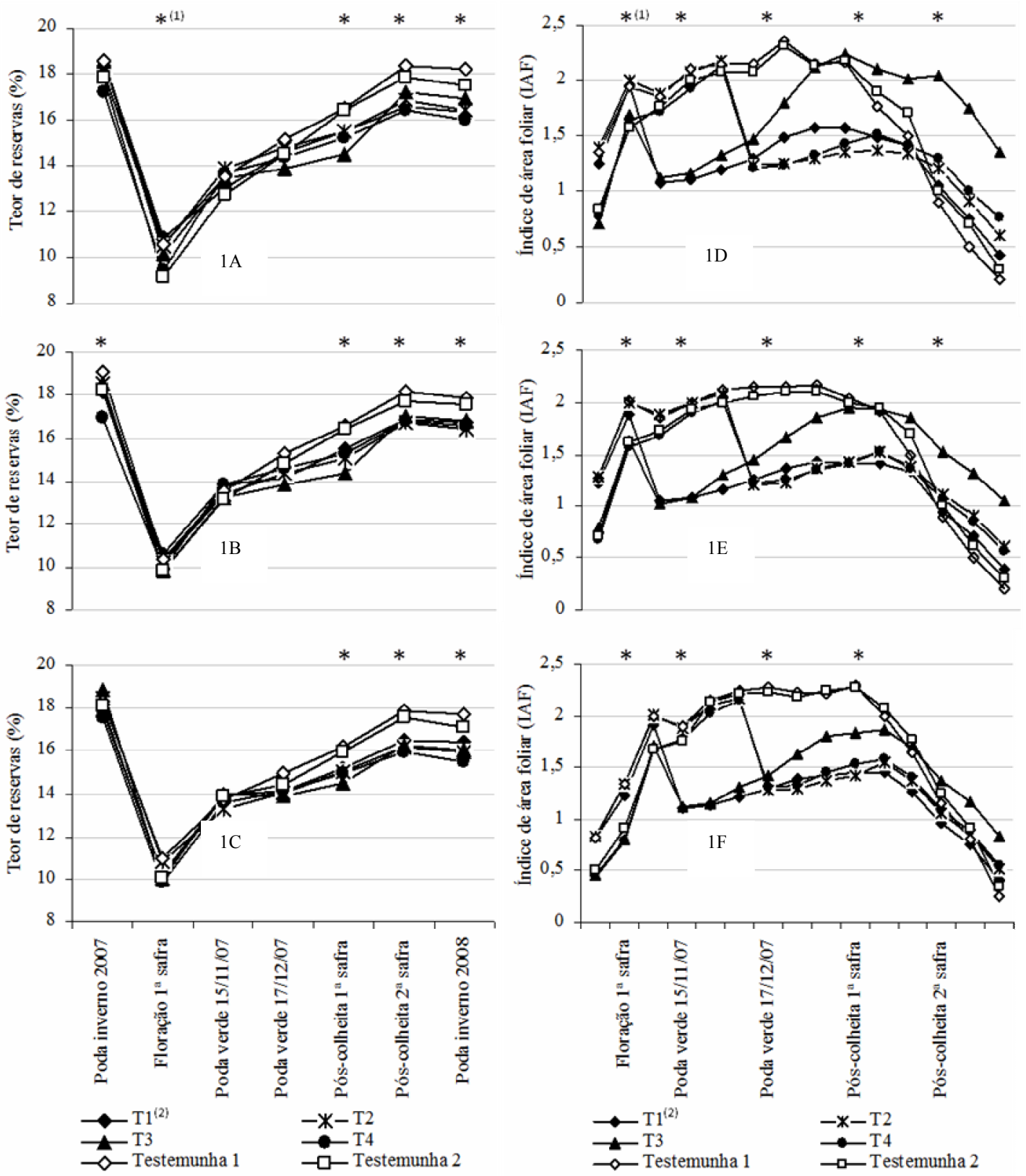

${ }^{(1)}$ Diferenças significativas no conteúdo de reservas dos ramos e IAF, dentro de cada etapa fenológica, pelo teste de Tukey $(\mathrm{p}<0,05)$, encontram-se assinalados com $(*)$.

(2) Testemunha 1 - Poda de inverno em julho - sem poda verde (PIJ), Testemunha 2 - Poda de inverno em agosto - sem poda verde (PIA); T1 - Poda de inverno em julho e poda verde em novembro (PIJ + PVN); T2 - Poda de inverno em julho e poda verde em dezembro (PIJ + PVD); T3 - Poda de inverno em agosto e poda verde em novembro (PIA + PVN); T4 - Poda de inverno em agosto e poda verde em dezembro (PIA + PVD).

Fonte: Elaboração dos autores. 
Da pós-colheita da segunda safra à poda de inverno de 2008, verificou-se um leve declínio no conteúdo de reservas nos ramos (Figuras 1A, 1B e $1 \mathrm{C})$. Esse decréscimo deveu-se à manutenção da taxa respiratória das plantas e a possível mobilização das reservas dos ramos para as estruturas permanentes da planta. No inverno, as reservas amiláceas são parcialmente convertidas em açúcares solúveis nos braços, tronco e raízes da videira (BATES; DUNST; JOY, 2002; ZAPATA et al., 2004). Esses carboidratos solúveis possuem função importante de resistência ao frio, bem como prover energia e substratos para o crescimento inicial das brotações na primavera (CARVALHO; ZANETTE, 2004).

De acordo com Giovaninni (2008), para um adequado desenvolvimento da videira na primavera, recomenda-se a manutenção das folhas na planta por maior tempo possível no outono, para a realização de fotossíntese e acúmulo de reservas nos tecidos. Em função do estudo não compreender a realização de uma amostragem na fase de abscisão foliar, um provável aumento de reservas nos ramos da póscolheita da segunda safra à queda das folhas da planta não foi observado na Figura 1.

De modo geral, a prática da poda verde conferiu às plantas um menor teor de substâncias de reservas totais nos ramos. A redução no nível dos carboidratos, ao final do ciclo vegetativo da videira submetida a duas safras, infere que tal manejo deve ser adotado com cuidado, sugerindose aplicá-lo a cada dois ciclos vegetativos para não debilitar demasiadamente a videira para as safras seguintes, na região da Depressão Central do Rio Grande do Sul. Além disso, sugere-se não deixar uma carga excessiva na primeira produção, para não comprometer a segunda produção e o estado energético das plantas.

\section{Conclusões}

1 - A execução de uma poda seca associada a uma poda verde permite a obtenção de duas safras de uva por ciclo vegetativo em 'Niagara Branca', 'Niagara Rosada' e 'Concord'.
2 - O rendimento da segunda safra é maior quando a poda seca é realizada em agosto associada à poda verde em novembro (fase ervilha do fruto).

3 - As brotações emitidas pela poda verde governam o índice de área foliar e a dinâmica de síntese/consumo das reservas nos ramos, em videiras submetidas à segunda produção.

4 - A realização de duas colheitas de uva por ciclo vegetativo provoca redução nas reservas acumuladas nos ramos ao final do ciclo da cultura.

\section{Referências}

ANZANELlO, R.; GONZATTO, M. P.; SOUZA, P. V. D. de. Produção de videiras 'Niagara Branca' e 'Concord' submetidas a duas safras por ciclo vegetativo na Depressão Central do Rio Grande do Sul. Scientia Agraria, Curitiba, v. 9, n. 3, p. 311-316, 2008.

BATES, T. R.; DUNST, R. M.; JOY, P. Seasonal dry matter, starch, and nutrient distribution in 'Concord' grapevine roots. Hortscience, Alexandria, v. 37, n. 2, p. 313-316, 2002.

BERGAMASCHI, H.; GUADAGNIN, M. R.; CARDOSO, L. S.; SILVA, M. I. G. da. Clima da estação experimental da UFRGS (e região de abrangência). Porto Alegre: Universidade Federal do Rio Grande do Sul, 2003. $78 \mathrm{p}$.

BENNETT, J.; JARVIS, P.; CREASY, G. L.; TROUGHT, M. C. T. Influence of defoliation on overwintering carbohydrate reserves, return bloom, and yield of mature Chardonnay grapevines. American Journal of Enology and Viticulture, Davis, v. 56, n. 4, p. 386-393, 2005.

BOLDING, H.; SMITH, G. S.; KLAGES, K. Seasonal concentration of non-structural carbohydrates of five Actinidia species in fruit, leaf and fine root tissue. Annals of Botany, Oxford, v. 85, n. 4, p. 469-476, 2003.

BORBA, M. R. C.; FILHO, J. A. S.; KLUGE, R. A. Teores de carboidratos em pessegueiros submetidos a diferentes intensidades de poda verde em clima tropical. Revista Brasileira de Futicultura, Jaboticabal, v. 27, n. 1, p. 68-72, 2005.

CAMARGO, U. A. Espécies e cultivares. In: KUHN, G. EMBRAPA: uvas para processamento e produção. Brasília: Embrapa Informação Tecnológica, 2003. p. 3444. (Frutas do Brasil, 34).

CARBONNEAU, A. Príncipes et méthodes de mesure de la surface foliaire. Essai de caractérisations des types de 
feuilles dans genre Vitis. Annales De L'amélioration Des Plantes, Paris, v. 26, n. 1, p. 327-43, 1976.

CARVALHO, R. I. N.; ZANETTE, F. Conteúdo de carboidratos em gemas e ramos de macieira durante o outono e inverno em região de baixa ocorrência de frio. Revista Brasileira de Fruticultura, Jaboticabal, v. 26, n. 2, p. 202-205, 2004.

CASTERAN, P. Conduit de la vigne. Sciences et techiniques de la vigne. Paris: Dunot, 1971. 719 p.

FERREE, D. C.; MCARTNEY, S. J.; SCURLOCK, D. $M$. Influence of irradiance and period of exposure on fruit set of French-American hybrid grapes. Journal of the American Society for Horticultural Science, Alexandria, v. 126, n. 3, p. 283-290, 2001.

FOCHESATO, M. L.; SOUZA, P. V. D. de; AGOSTINI, S. Obtenção de duas safras por ciclo vegetativo pelo manejo da poda. Revista Agropecuária Catarinense, Florianópolis, v. 20, n. 1, p. 53-57, 2007.

GIOVANINNI, E. Produção de uvas para vinhos, suco e mesa. 3. ed. Porto Alegre: Renascença, 2008. 362 p.

KELLER, M.; MILLS, L. J.; WAMPLE, R. L.; SPAYD, S. E. Cluster thinning effects on three deficit-irrigated Vitis vinifera cultivars. American Journal of Enology and Viticulture, Davis, v. 56, n. 2, p. 91-102, 2005.

KLIEWER, W. M.; DOKOOZLIAN, N. K. Leaf area/ crop weight ratios of grapevines: influence on fruits compositions and wine quality. American Journal Enology and Viticulture, Davis, v. 56, n. 2, p. 170-181, 2005.

LEBON, G.; WOJNAROWIEZ, G.; HOLZAPFEL, B.; FONTAINE, F.; VAILLANT-GAVEAU, N.; CLEMENT, C. Sugars and flowering in the grapevine (Vitis vinifera L.). Journal of Experimental Botany, Oxford, v. 59, n. 15, p. 2565-2578, 2008.

MADERO, E. T.; LÓPEZ, I. M. Efecto de la fecha em verde y del aclareo de racimos sobre la obtención de uma segunda cosecha de uva de mesa. Revista de la Facultat de Agronomia, Buenos Aires, v. 10, n. 1, p. 228-229, 1993.

MARENCO, R. A.; LOPES, N. F. Fisiologia vegetal: fotossíntese, respiração, relações hídricas e nutrição mineral. Viçosa: Universidade Federal de Viçosa, 2005. $451 \mathrm{p}$.

MULLINS, M. G.; BOUQUET, A.; WILLIAMS, L. E. Biology of the grapevine. Cambridge: University Press, 2000. 239 p.

OLIVEIRA, P. B.; SILVA, M. J.; FERREIRA, R. B.; OLIVEIRA, C. M.; MONTEIRO, A. A. Dry matter partitioning, carbohydrate composition, protein reserves, and fruiting in 'Autumn bliss' red raspberry vary in response to pruning date and cane density. Hortscience, Alexandria, v. 42, n. 1, p. 77-82, 2007.

PRIESTLEY, G. A. A new method for the estimation of the resources of apple trees. Journal of the Science of Food and Agriculture, London, v. 16, n. 12, p. 717-721, 1965.

RICCE, W. S.; CARAMORI, P. H.; ROBERTO, S. R. Potencial climático para a produção de uvas em sistema de dupla poda anual no estado do Paraná. Bragantia, Campinas, v. 72, n. 4, p. 408-415, 2013.

SANTOS, A. O.; HERNANDES, J. L.; PEDRO JUNIOR, M. J.; PEREIRA, S. E. Composição da produção e qualidade da uva em videira cultivada sob dupla poda e regime microclimático estacional contrastante. Revista Brasileira de Fruticultura, Jaboticabal, v. 33, n. 4, p. 1135-1154, 2011.

SANTOS, C. M. G.; MOREIRA, M. M.; RODRIGUES, J. D. Metabolismo da videira 'syrah' no semiárido nordestino sob três estratégias hídricas. Semina: Ciências Agrárias, Londrina, v. 34, n. 6, p. 3611-3624, 2013.

SHALTOUT, A.; SALEM, A. T.; KILANY, A. Effect of pre-bloom sprays and soil drenches of paclobutrazol on growth, yield, and fruit composition of 'Roumi Red' grapes. Journal of the American Society for Horticultural Science, Alexandria, v. 113, n. 1, p. 13-17, 1988.

SMITH, J. P.; HOLZAPFEL, B. P. Cumulative responses of semillon grapevines to late season perturbation of carbohydrate reserve status. American Journal of Enology and Viticulture, Davis, v. 60, n. 2, p. 461-470, 2009.

SOUZA, P. V. D. de; FOCHESATO, M. L. Emprego da poda verde para obtenção de duas safras por ciclo vegetativo em 'Niagara Branca'. Bragantia, Campinas, v. 66, n. 4, p. 527-533, 2007.

ZAPATA, C.; DELEENS, E.; CHAILLOU, S.; MAGNE, C. Partitioning and mobilization of starch and $\mathrm{N}$ reserves in grapevine (Vitis vinifera L.). Journal of Plant Physiology, Heidelberg, v. 161, n. 9, p. 1031-1040, 2004.

WERMELINGER, B.; BAUMGÄRTNERAND, J.; GUTIERREZ, A. P. A demographic model of assimilation and allocation of carbon and nitrogen in grapevines. Ecological Modelling, Amsterdam, v. 53, n. 1, p. 1-26, 1991.

YOSHIOKA, H.; NAGAI, K.; AOBA, K.; FUKUMOTO, M. Seasonal changes of carbohydrates metabolism in apple trees. Scientia Horticulturae, Amsterdam, v. 36, n. 3, p. 219-227, 1988. 
